\title{
Predicting maximal oxygen uptake from a 3-minute progressive knee-ups and step test
} \author{
Ting Chen Corresp. 5 \\ ${ }^{1}$ Center of General Education, Taipei Medical University, Taipei, Taiwan \\ 2 Service System Technology Center, Industrial Technology Research Institute, Hsinchu, Taiwan \\ 3 Department of Combat Sports and Chinese Martial Arts, Chinese Culture University, Taipei, Taiwan \\ 4 Graduate Institute of Sports Science, National Taiwan Sport University, Taoyuan, Taiwan \\ 5 Physical Education Office, Ming Chuan University, Taipei, Taiwan \\ Corresponding Author: Hung-Ting Chen \\ Email address: simondr@mcu.mail.edu.tw
}

Yu-Chun Chung ${ }^{1}$, Ching-Yu Huang ${ }^{2}$, Huey-June Wu ${ }^{3}$, Nai-Wen Kan ${ }^{1}$, Chin-Shan Ho ${ }^{4}$, Chi-Chang Huang ${ }^{4}$, Hung-

Background. Cardiorespiratory fitness assessment is crucial for diagnosing health risks and assessing interventions. Direct measurement of maximum oxygen uptake $\left(\mathrm{VO}_{2} \max \right)$ yields more objective and accurate results, but it is practical only in a laboratory setting. We therefore investigated whether a 3-min progressive knee-up and step (3MPKS) test can be used to estimate peak oxygen uptake in these settings. Method. The data of 166 healthy adult participants were analyzed. We conducted a $\mathrm{VO}_{2}$ max test and a subsequent 3MPKS exercise test, in a balanced order, a week later. In a multivariate regression model, sex; age; relative $\mathrm{VO}_{2}$ max; body mass index (BMI); body fat percentage (BF\%); resting heart rate (HRO); and heart rates at the beginning as well as at the first, second, third, and fourth minutes (denoted by HRO, HR1, HR2, HR3, and HR4, respectively) during a step test were used as predictors. Moreover, $R^{2}$ and standard error of estimate (SEE) were used to evaluate the accuracy of various body composition models in predicting $\mathrm{VO}_{2}$ max. Results. The predicted and actual $\mathrm{VO}_{2}$ max values were significantly correlated ( $\mathrm{BF} \%$ model: $R^{2}=$ 0.624, SEE $=4.982 ; \mathrm{BMI}$ model: $\left.R^{2}=0.567, \mathrm{SEE}=5.153\right)$. The $\mathrm{BF} \%$ model yielded more accurate predictions, and the model predictors were sex, age, BF\%, HRO, $\triangle \mathrm{HR} 3-\mathrm{HR} 0$, and $\triangle H R 3$ - HR4. Conclusion. In our study, involving Taiwanese adults, we constructed and verified a model to predict $\mathrm{VO}_{2}$ max, which indicates cardiorespiratory fitness. This model had the predictors sex, age, body composition, and heart rate changes during a step test. Our 3MPKS test has the potential to be widely used in epidemiological research to measure $\mathrm{VO}_{2}$ max and other health-related parameters. 
1 Predicting maximal oxygen uptake from a 3-minute progressive knee-ups and step test

3 Yu-Chun Chung ${ }^{1}$, Ching-Yu Huang ${ }^{2}$, Huey-June Wu ${ }^{3}$, Nai-Wen Kan ${ }^{1}$, Chin-Shan Ho ${ }^{4}$,

\section{Chi-Chang Huang 4 , Hung-Ting Chen 5}

$5 \quad{ }^{1}$ Center of General Education, Taipei Medical University, Taipei, Taiwan

$6 \quad{ }^{2}$ Service System Technology Center, Industrial Technology Research Institute, Hsinchu, Taiwan

$7 \quad{ }^{3}$ Department of Combat Sports and Chinese Martial Arts, Chinese Culture University, Taipei, Taiwan

$8{ }^{4}$ Graduate Institute of Sports Science, National Taiwan Sport University, Taoyuan, Taiwan

$9 \quad{ }^{5}$ Physical Education Office, Ming Chuan University, Taipei, Taiwan

10

12 Corresponding author:

13 Hung-Ting Chen,

14 E-mail: simondr@mail.mcu.edu.tw

15

16 


\section{Abstract}

18 Background. Cardiorespiratory fitness assessment is crucial for diagnosing health risks and

19 assessing interventions. Direct measurement of maximum oxygen uptake $\left(\mathrm{VO}_{2}\right.$ max $)$ yields more

20 objective and accurate results, but it is practical only in a laboratory setting. We therefore

21 investigated whether a 3-min progressive knee-up and step (3MPKS) test can be used to estimate

22 peak oxygen uptake in these settings.

23 Method. The data of 166 healthy adult participants were analyzed. We conducted a $\mathrm{VO}_{2} \max$

24 test and a subsequent 3MPKS exercise test, in a balanced order, a week later. In a multivariate

25 regression model, sex; age; relative $\mathrm{VO}_{2}$ max; body mass index (BMI); body fat percentage

26 (BF\%); resting heart rate (HR0); and heart rates at the beginning as well as at the first, second,

27 third, and fourth minutes (denoted by HR0, HR1, HR2, HR3, and HR4, respectively) during a

28 step test were used as predictors. Moreover, $R^{2}$ and standard error of estimate (SEE) were used to

29 evaluate the accuracy of various body composition models in predicting $\mathrm{VO}_{2}$ max.

30 Results. The predicted and actual $\mathrm{VO}_{2}$ max values were significantly correlated (BF\% model: $R^{2}$

$31=0.624, \mathrm{SEE}=4.982 ; \mathrm{BMI}$ model: $\left.R^{2}=0.567, \mathrm{SEE}=5.153\right)$. The $\mathrm{BF} \%$ model yielded more

32 accurate predictions, and the model predictors were sex, age, BF\%, HR0, $\Delta \mathrm{HR} 3-\mathrm{HR} 0$, and

$33 \quad \Delta$ HR3 - HR4.

34 Conclusion. In our study, involving Taiwanese adults, we constructed and verified a model to

35 predict $\mathrm{VO}_{2}$ max, which indicates cardiorespiratory fitness. This model had the predictors sex, 
36 age, body composition, and heart rate changes during a step test. Our 3MPKS test has the

37 potential to be widely used in epidemiological research to measure $\mathrm{VO}_{2}$ max and other health-

38 related parameters.

39

40 Keywords: Aerobic ability, 3-min Harvard step test, Cardiovascular function, Field tests

41 


\section{Introduction}

43 In 2016, the American Heart Association launched a series of publications promoting the clinical

44 evaluation of cardiorespiratory fitness (CRF) with the overall aim of improving the prevention

45 and treatment of cardiovascular disease (CVD; Ross et al., 2016). Furthermore, the association

46 urged the US federal government to compile a registered CRF database (Kaminsky et al., 2013);

47 this highlights the importance of CRF. CRF is generally defined as the integrated ability to

48 transport oxygen from the atmosphere to the mitochondria for physical activity. Notably, CRF

49 involves the respiratory, circulatory, and neuromuscular systems and has a clear and direct

50 relationship with the functions of various systems. Individuals with weak CRF have an up to

$5170 \%$ all-cause mortality rate and 56\% cardiovascular mortality rate (Kodama et al., 2019).

52 Similarly, every 1-MET increase in athletic ability reduces all-cause mortality and cardiovascular

53 mortality rates by $15 \%$ and $13 \%$, respectively (Kodama et al., 2019). Numerous studies have

54 suggested that CRF and CVD are related to all-cause mortality and cancer mortality (Blair et al.,

55 1989; Laukkanen et al., 2004; Sawada et al., 2014; Sui et al., 2007). A recent meta-analysis

56 reported CRF to be a predictor of the risk of sudden cardiac death (Jiménez-Pavón et al., 2019).

57 Therefore, CRF assessment is crucial for diagnosing health risks and assessing interventions.

58 CRF can be measured using the respiratory data of exercising participants. Specifically, these

59 data are used to calculate maximal oxygen uptake $\left(\mathrm{VO}_{2} \max \right)$, the gold standard for CRF

60 measurement; in the measurement, participants either run on a treadmill or use an ergometer at 
61 an exercise intensity that increases progressively until a given maximum is reached. Although

62 submaximal exercise models and nonexercise models (without an exercise test) are alternatives

63 for estimating $\mathrm{VO}_{2}$ max in measuring CRF (Abut et al., 2016), the direct measurement of $\mathrm{VO}_{2}$

64 max yields more objective and accurate results. However, such measurement is inconvenient

65 because it requires expensive equipment and well-trained experimenters. In addition, participants

66 perceive such measurement tests to be exhausting, time-consuming, and relatively risky and are

67 thus less willing to participate. Accordingly, researchers have developed various submaximal

68 exercise tests to indirectly estimate $\mathrm{VO}_{2}$ max; moreover, retrospective studies conducted by the

69 American Heart Association have demonstrated that CRF indicators, whether directly measured

70 or indirectly estimated, are robust indicators of health (Ross et al., 2016).

71 Submaximal exercise is a common method for estimating $\mathrm{VO}_{2}$ max, particularly in

72 epidemiological research and large-scale physical fitness testing that involve numerous

73 participants. The field tests in these measurement procedures include running, shuttle running,

74 and the step test, with the step test being the most common method for evaluating cardiovascular

75 function (Grant et al., 1999). In particular, the YMCA step test is widely used to predict $\mathrm{VO}_{2}$

$76 \max$ (Beutner et al., 2015). Currently, the Sports Administration of Taiwan's Ministry of

77 Education uses the 3-min Harvard step test for its National Physical Fitness and Cardiovascular

78 Test. Specifically, three heart rate measurements are used to calculate the step-up index.

79 However, previous studies have reported considerable differences in the validity of using the step 
80 test index to evaluate $\mathrm{VO}_{2}$ max, with the corresponding correlation coefficient (R) being $0.35-$

810.94 (Buckley et al., 2004; Chang and Lin, 1995; Mazic et al., 2001; Su, Lin, \& Hsieh, 2006;

82 Chang and Lin, 1995; Yoopat et al., 2002). Furthermore, step tests require the use of step-up

83 boxes, and the overall test time must be at least 6 min to allow for heart rate recovery.

84 Participants who are less physically fit or who have knee conditions may find it difficult to

85 complete the test and may also fall in the process of going up and down the stairs. A team of

86 Japanese researchers developed a new 3-min walking test (Cao et al., 2013). Specifically, their

87 main evaluation criteria comprised participant characteristics such as age, sex, and BMI as well

88 as participants' RPE during exercise. These criteria were determined to be effective predictors of

$89 \mathrm{VO}_{2}$ max, and participants thought that this method was quicker and easier.

90 Tests of general CRF are crucial to the clinical evaluation of CVD. Additionally, the

91 advantages and disadvantages, such as venue size, participant willingness, and the instruments,

92 of various past field tests should be considered during the formulation of new methods, as done

93 in the present study. Accordingly, we conducted the present study with the aim of developing a

94 rapid, convenient, and low-risk model that can predict $\mathrm{VO}_{2}$ max in Taiwanese adults.

95 Additionally, our model accords with the principle that physical exercise ought to be progressive.

96 We investigated the feasibility of using a 3-min progressive knee-ups and step (3MPKS) test to

97 predict $\mathrm{VO}_{2} \max$. 
99 Materials and Methods

100 Participants

101 Prospective participants were excluded if they (1) had cardiovascular, pulmonary, or

102 metabolic diseases; (2) had neurological, muscular, or skeletal disorders that affected their

103 athletic ability; (3) had other health conditions that made them unsuited for moderate or intense

104 exercise; or (4) were taking medications that could affect the outcome of this study. In total,

105 among 200 participants recruited for this experiment, 166 completed the test. The data of the 166

106 participants were included in the analysis (age: 20-64 years; 65 men, 101 women). Among the

10734 participants excluded, 1 participant withdrew from the experiment after experiencing

108 suspected symptoms of arrhythmia during exercise; 11 were excluded because they failed to

109 complete the step test within the requisite time ( $3 \mathrm{~min}) ; 12$ were excluded because they could not

110 attain the requisite step frequency and knee height for 20 consecutive seconds; 9 were excluded

111 because they had missing or improperly measured heart rate data; and 1 was excluded for having

112 a " 0 " in their heart rate data. All participants signed an informed consent form after

113 understanding their rights, the risks when participating in this study, and the purpose and method

114 of our research. Our research plan was approved by the Institutional Review Boards (IRBs) of

115 the Industrial Technology Research Institute and of Taipei Medical University (IRB No:

116 N201808055). Participant characteristics are detailed in Table 1.

117 


\section{Procedure}

119 The anthropometric and body composition measures were height, weight, and body fat

120 percentage $(\mathrm{BF} \%)$. BF\% was measured using bioelectrical impedance analysis (InBody 720 ,

121 Biospace, USA; McLester et al., 2020), and body mass index (BMI, in $\mathrm{kg} / \mathrm{m}^{2}$ ) was calculated as

122 the quotient that is weight (in kilograms) divided by the squared height (in meters).

123 We conducted two exercise tests in a counterbalanced design. The second test was

124 conducted exactly 1 week after the first and at the same time of the day to ensure that the

125 participants recovered adequately from the first exercise. The participants underwent $5-10 \mathrm{~min}$

126 of dynamic warm-up prior to both exercise tests; to mitigate extraneous influence on the results,

127 the participants were also asked not to engage in moderate or intense exercise $48 \mathrm{~h}$ before both

128 exercise tests.

129 To measure the $\mathrm{VO}_{2}$ max of the participants, we used a bicycle ergometer (839E, Monark,

130 Varberg, Sweden) for a maximal graded exercise test. After participants sat still for 2 min, they

131 sat on the stationary bicycle and started cycling at the speed of $70 \pm 10 \mathrm{rpm}$. The participants

132 began the exercise with a 2-min warm-up at $25 \mathrm{~W}$ loading, where the loading was increased by

$13315 \mathrm{~W}$ every $2 \mathrm{~min}$. The testing was terminated when the participants could no longer continue

134 the exercise due to bradypnea or fatigue, although the bicycle speed was maintained at $70 \mathrm{rpm}$.

135 Subsequently, the participants rested for $3 \mathrm{~min}$ at a loading of $0 \mathrm{~W}$ (no resistance). Throughout

136 the exercise testing, the participants wore a watch to monitor their heart rate and a mask to 
137 monitor their breathing. Breath-by-breath analysis was conducted on the participant data through

138 a cardiopulmonary testing system (MetaMax 3B, Cortex, Germany). $\mathrm{VO}_{2}$ max was defined as the

139 maximum average oxygen uptake for 20 consecutive seconds. To ensure that every participant

140 reached $\mathrm{VO}_{2}$ max, we defined $\mathrm{VO}_{2}$ max as being reached if two of the three following conditions

141 were met: (1) $\mathrm{VO}_{2}$ plateaus with increases in work rate; (2) the maximum respiratory exchange

142 ratio is $\geq 1.10$; and (3) $90 \%$ of the expected maximal heart rate, obtained by subtracting the

143 participant's age from 220, is reached (American College of Sports Medicine 2009). Nearly all

144 participants satisfied the criteria for an acceptable $\mathrm{VO}_{2}$ max, with only one participant excluded

145 from the $\mathrm{VO}_{2}$ max test due to suspected symptoms of arrhythmia observed in the step test.

\section{3MPKS test}

148 Prior to the 3MPKS test, the participants wore a sports watch with heart rate (Polar V800,

149 USA) and stride sensors (Polar S3 BlueTooth Stride Sensor, USA). The heart rate sensor was

150 placed at the center of each participant's chest using a heart rate belt (Polar H10), and the step

151 sensor was fixed on a pair of shoes, with shoelaces, to monitor their heartbeat and number of

152 steps taken. After the devices were worn, we measured the midpoint of the line connecting the

153 anterior epicondyle to the midpoint of the sacrum. We marked the midpoint on the wall using

154 colored tape as a reference for the height at which the knee should be lifted to when stepping.

155 After the test started, the participants followed the appropriate rhythm and were required to lift 
156 their knee to the marked height at each step. The participants began the test at a pace of $80 \mathrm{spm}$

157 (steps per minute), which increased by $16 \mathrm{spm}$ every $30 \mathrm{~s}$ in six stages. The participants walked

158 in stages 1 to 4 and had to perform stationary running in stages 5 and 6 (Figure 1). We stopped

159 the exercise if the participants could not achieve the requisite knee height or rhythm for $30 \mathrm{~s}$. For

160 their safety, the participants were asked to relax at a step rate of $80 \mathrm{spm}$ in the first $30 \mathrm{~s}$ before

161 resting in a standing position. We recorded the participants' heart rate during the exercise, at the

162 end of the exercise, and 1 min after the end of the exercise. Thirty-four participants were

163 excluded because (1) their heart rate data were missing, (2) their heart rate was $0,(3)$ they did not

164 maintain the requisite step frequency or knee height for 20 consecutive seconds, (4) they failed to

165 complete the step test within the requisite duration, and (5) they were suspected of having heart

166 arrhythmia. Potential predictor variables for the results of the 3MPKS test were based on per-

167 second heart rate data collected during the test. The data included heart rate at the beginning as

168 well as at the first, second, third, and fourth minutes, denoted by HR0, HR1, HR2, HR3, and

169 HR4, respectively, and were used for subsequent analysis.

170

171 Statistical analyses

172 To construct and subsequently evaluate a model for estimating relative oxygen uptake, we

173 divided the full sample set $(n=166)$ into a $75 \%$ training sample set $(n=124)$ and $25 \%$ test 
174 sample set through simple random sampling. We analyzed the descriptive statistics for the main

175 parameters, for the whole sample, and for the two subsamples.

176

177 Development of prediction model

178 Using Pearson correlation coefficients, we examined the relationship between the predicted

179 and actual relative oxygen uptakes. Multiple regression analysis was used to construct a method

180 for selecting which variables to include in the model for predicting relative oxygen uptake.

181 Through a backward-selection regression approach, the initial model included all possible

182 predictors, including sex $(\operatorname{men}=1$, women $=0)$, age, BMI, BF\%, HR0, HR1, HR2, HR3, HR4,

$183 \Delta \mathrm{HR} 0-\mathrm{HR} 1, \Delta \mathrm{HR} 1-\mathrm{HR} 2, \Delta \mathrm{HR} 2-\mathrm{HR} 3, \Delta \mathrm{HR} 3-\mathrm{HR} 0$, and $\triangle \mathrm{HR} 3-\mathrm{HR} 4$. Additionally, we

184 constructed a BMI model and BF\% model to predict body composition. The goodness of fit and

185 precision of the regression equations were evaluated using the multiple coefficient of

186 determination $\left(R^{2}\right)$, absolute standard error of estimate (SEE), and relative SEE (\%SEE).

187 To construct an accurate regression model, the regression assumptions were verified. We

188 conducted a Kolmogorov-Smirnov test to examine the normality of the residuals, and we

189 calculated the variation inflation factor (VIF) to check for multicollinearity.

190 All statistical analyses were performed using SPSS version 20 (IBM, USA). Statistical

191 significance was indicated by an alpha level of 0.05 .

192 
193

194

\section{Results}

of them were men. Their mean relative oxygen uptake was $34.45 \pm 8.69 \mathrm{~mL} / \mathrm{kg} / \mathrm{min}$. The training sample and test sample did not differ significantly with respect to their parameter values $(p>$ 0.05) (Table 1). the intraclass correlation coefficient (ICC) was 0.88 (95\% confidence interval [CI]: 0.77-0.94), and 60 Taiwanese adults tested 1 week apart participated in this evaluation. In general, good, moderate, and poor reliability levels are indicated by ICC values of $>0.75,0.5-0.75$, and $<0.5$, respectively.

According to the correlation matrix, $\mathrm{VO}_{2}$ max had the strongest correlation with $\mathrm{BF} \%$ among all variables $(R=-0.662$; training data set, $\mathrm{n}=124)$. In addition, $\mathrm{VO}_{2}$ max was significantly correlated with the heart rate parameters (HR0, HR2, HR3, and HR4), whose data and HR3 $(R=-0.289)$, respectively. Despite the high correlation between $\mathrm{VO}_{2}$ max and the heart rate parameters at different stages, the heart rates of the participants were expected to increase

211 continuously from the first to third minutes of stepping, if performed properly. An individual's 
212 heart rate typically reaches its peak immediately after exercise, and it either decreases at $1 \mathrm{~min}$

213 after exercise or does not decrease at all depending on whether the individual recovers quickly or

214 poorly. Because heart rate is dynamic, to establish a regression model, we used combinations of

215 heart rate parameters and adopted the difference between predicted and measured heart rate data

216 at each stage as inputs (Table 2).

217 The results of our other cross-validation analyses are presented in terms of CE (Constant

218 error) values. The absolute CE values for subgroups stratified by sex and age were $<1.00$ for the

219 two models (both in training and testing data sets, $n=124$ and 42). Regarding the subgroups

220 stratified by $\mathrm{VO}_{2}$ max, the $\mathrm{CE}$ values were negative in low-fitness, middle-fitness subgroups in

221 training data set and low-fitness in testing data set. On the other hand, the CE values were

222 positive in high-fitness in all two data sets (Table 3).

223 Figures 2 and 3 present the Bland-Altman plots produced by the BF\% and BMI models

224 based on the testing data set $(n=42)$. As evident in the plots, the differences between the

225 predicted and measured data were within an acceptable range. The mean error of the $\mathrm{BF} \%$ model

226 was $-0.36 \mathrm{~mL} / \mathrm{kg} / \mathrm{min}(95 \% \mathrm{CI}=-12.38$ to 11.98$)$. For the BMI model, the mean error was 0.4

$227 \mathrm{~mL} / \mathrm{kg} / \mathrm{min}(95 \% \mathrm{CI}=-12.35$ to 13.58$)$. In the BF\% and BMI models, the errors for three and

228 two participants, respectively, fell outside the $95 \%$ CI.

229 We constructed a model to predict relative oxygen uptake by using multiple regression

230 analysis. The parameters selected for the BF\% model were sex, age, BF\%, HR0, $\Delta \mathrm{HR} 3-\mathrm{HR} 0$, 
231 and $\Delta \mathrm{HR} 3-\mathrm{HR} 4 ; R^{2}=0.624$ and $\mathrm{SEE}=4.982$ (training data set, $\mathrm{n}=124$ ) (Figure 4). The

232 parameters selected for the BMI model were sex, age, BMI, initial heart rate, $\triangle \mathrm{HR} 3$ - HR0, and

$233 \Delta \mathrm{HR} 3-\mathrm{HR} 4 ; R^{2}=0.567$ and $\mathrm{SEE}=5.153($ training data set, $\mathrm{n}=124)$ (Figure 5). We used $\mathrm{BF} \%$

234 as a predictor of body composition; it is more accurate relative to BMI, which is calculated using

235 only height and weight (Table 4). Table 4 presents the cross-validation results for the predicted

236 residual sum of squares (PRESS) statistics $\left(R^{2} p=0.64\right.$ and SEE $\left.p=4.84\right)$, which demonstrated

237 minimal shrinkage in the accuracy of the regression model.

238 All regression assumptions were satisfied in our $\mathrm{VO}_{2}$ max prediction models. Specifically,

239 the Kolmogorov-Smirnov test indicated normality in the residuals $(p>0.05)$. No pattern was

240 determined in the scatter plot between the residuals and predicted $\mathrm{VO}_{2}$ max. Multicollinearity

241 was absent among the predictor variables: the VIF ranges for the $\mathrm{BF} \%$ and $\mathrm{BMI}$ models were

242 1.09-1.49 and 1.10-1.40, respectively; multicollinearity is absent if VIF $\leq 10$ (O'Brien 2007).

244 Discussion

245 This study developed a practical and easy-to-use model for predicting $\mathrm{VO}_{2}$ max in

246 Taiwanese people. We recruited 166 Taiwanese adults and constructed and then evaluated a

247 prediction model. Our results suggest that age, sex, and $\mathrm{BF} \%$ as well as heart rate during the step

248 test are excellent predictors of $\mathrm{VO}_{2}$ max. We also developed a novel 3MPKS test. 
251 physical activity, and resting heart rate) to be excellent predictors of $\mathrm{VO}_{2}$ max; for their model,

$252 R^{2}$ was 0.61 and SEE was $5.70 \mathrm{~mL} / \mathrm{kg} / \mathrm{min}$ for men, and $R^{2}$ was 0.56 and SEE was 5.14

$253 \mathrm{~mL} / \mathrm{kg} / \mathrm{min}$ for women. Jackson et al. (2012) conducted a 27-year study that examined the $\mathrm{VO}_{2}$

254 max of 11,365 people and used variables such as age, sex, BMI, waist circumference, resting

255 heart rate, physical activity, and smoking habits to estimate CRF; for their model, $R$ was $0.78-$

2560.81 and SEE was $5.3-5.6 \mathrm{~mL} / \mathrm{kg} / \mathrm{min}$. Although the nonexercise model is an excellent predictor

257 of $\mathrm{VO}_{2}$ max, its SEE is generally higher than those of submaximal exercise models; compared

258 with nonexercise models, our developed $\mathrm{BF} \%$ model had better predictive performance and a

259 lower standard error of estimate $\left(R^{2}=0.624\right.$ and SEE $\left.=4.982\right)$. Abut et al. (2016) reported that

260 (1) when perceived functional ability (PFA) was used as the sole predictor of $\mathrm{VO}_{2} \max$, an $R$

261 value of 0.73 and a higher RMSE of $6.08 \mathrm{~mL} / \mathrm{kg} / \mathrm{min}$ could be obtained; (2) when submaximal

262 ending speed (SM-ES) of a treadmill was used as the sole predictor, the $R$ value increased to 0.82

263 and the RMSE was relatively low at $4.99 \mathrm{~mL} / \mathrm{kg} / \mathrm{min}$; and (3) when both PFA and SM-ES were

264 used as predictors, the $R$ value was 0.89 and RMSE was $4.14 \mathrm{~mL} / \mathrm{kg} / \mathrm{min}$. These findings

265 indicate that predicted values of $\mathrm{VO}_{2}$ max that are based only on participant self-reports are

266 likely to deviate from their measured values. Although predictive performance is ostensibly 
267 improved when motion is added to the prediction model, the cost of exercise tests due to the use

268 of this method restricts its application in large-scale tests.

269 Several studies have developed simple models involving submaximal motion. Lee et al.

270 (2019) investigated 568 adults and used sex, age, height, and weight and inverse recovery heart

271 rate during a YMCA step test to predict $\mathrm{VO}_{2}$ max; for their model, $R$ was 0.78 and SEE was 4.74

$272 \mathrm{~mL} / \mathrm{kg} / \mathrm{min}$. The duration of their exercise test plus recovery time was only $4 \mathrm{~min}$, and they used

273 exercise-induced heart rate as a predictor; their results are similar to ours. Their study provided a

274 simple and practical method for simultaneously estimating CRF in many Korean adults. Cao et

275 al. (2013) used age, sex, and physical composition as well as stepping distance over a 3-min

276 period to develop a set of prediction methods. They determined that BF\% (a measure of body

277 composition) was a better predictor than $\mathrm{BMI}\left(R^{2}=0.83\right.$ vs. $0.80, \mathrm{SEE}=4.565$ vs. 5.037

$278 \mathrm{~mL} / \mathrm{kg} / \mathrm{min}$ ). In contrast to our method, their method has the considerable advantages of a shorter

279 testing time of $3 \mathrm{~min}$ and the fact that participants need not wear a heart rate monitor. However,

280 their test is limited by its need for a 20 -m open space. Similarly, we found that sex, age, and

$281 \mathrm{BF} \%$ as well as heart rate during the 3MPKS test yielded the best prediction performance $(R=$

$2820.79, \mathrm{SEE}=4.982 \mathrm{~mL} / \mathrm{kg} / \mathrm{min}$ ). Because BMI is based on only height and weight and may not

283 accurately represent the body characteristics of participants, BMI is a less accurate predictor than

$284 \mathrm{BF} \%$. 

counterparts, Asian adults have shorter heights and leg lengths when standing (Stanfield et al., 2012). Therefore, differences in heart rate and oxygen consumption potentially affect the model's prediction. The 3MPKS test employs the knee-ups and step test to measure the physical fitness and cardiopulmonary endurance of older adults (Rikli and Jones, 2001). In the test, participants must execute tasks at various knee heights based on their thigh length, and individualized exercise testing goals are provided. Moreover, most field tests involve average speed tests, such as step tests and running. In running tests specifically, if the distance is used as the capacity index but the speed or frequency of exercise is not progressively increased, participants may exercise intensely at the beginning of the test (i.e., run at a higher speed).

297 However, due to the lack of appropriate speed allocation, decremental loading occurs in participants as their physical strength decreases. The difficulty of diagnosing potential heart

299 diseases in advance increases the risk of sudden death during running tests. To the best of our

300 knowledge, research has not been conducted on the ethics of running tests. Most previous studies

301 have investigated the rate of sudden death among athletes in long-distance competitions.

302 However, cases of sudden cardiac death occur frequently worldwide during running tests, and 303 the principle that physical activities ought to be progressive must be adhered to in physical 
304 fitness tests. Our research method used body composition and heart rate as variables. The

305 advantages of the 3MPKS test are that it does not require a step-up box and is not subject to

306 venue restrictions. These make the 3MPKS test accord with the principle that physical activities

307 ought to be progressive, thus making it safer.

308 Considering the immediacy of heart rate measurement and that of confounding factors, we

309 used a chest-worn heart rate monitor in the experiment. Although the requirement of heart rate

310 monitoring constitutes a disadvantage for the 3MPKS test, it is ameliorated by the prevalence of

311 low-cost wearable devices. More comfortable than the chest-worn heart rate belt, products that

312 combine running clothes with heart rate belts have also appeared on the market. Research has

313 also suggested a high correlation between the heart rate measurements of various types of optical

314 devices and chest-worn heart rate belts (Stahl et al., 2016). Therefore, when conducting a large-

315 scale cardiorespiratory general test, the use of easily wearable optical heart rate monitors can be

316 considered. The whole-range monitoring of heart rate can also considerably improve test safety

317 in a field study. Notably, through whole-range monitoring, we found that one research

318 participant was likely to have an unknown heart disease. We then terminated the experiment for

319 the participant and recommended that the participant seek medical treatment. This example

320 illustrates a side benefit of CRF tests.

321 In our research model, heart rate during stepping at each stage was used as the main

322 variable. Therefore, the test may be unsuitable for individuals who have psychological sensitivity 
323 or dysautonomia or who are taking medication. Furthermore, because our participants were

324 adults between 20 and 64 years old, it was unclear whether our 3MKPS test is appropriate as a

325 physical fitness and cardiorespiratory test for students (7-23 years old) and older adults ( $\geq 65$

326 years old). Future research must include samples with greater diversity in age and ethnicity to

327 assess whether our 3MKPS test can be applied to the wider global population.

328

329 Conclusion

330 This study, involving Taiwanese adults, constructed and verified a model for predicting $\mathrm{VO}_{2}$

331 max, which is used to measure CRF. This model comprises the predictors sex, age, and body

332 composition as well as heart rate changes during a step test. Our 3MKPS test has three

333 advantages: it has a short testing time of $4 \mathrm{~min}$, it has no venue limitations, and it does not

334 require a step box. Furthermore, measurements can be taken for many participants

335 simultaneously by asking them to wear a heart rate monitor and move according to a beat. Our

336 model can also be applied to large-scale epidemiological research. In future applications, the

337 model can be combined with smartwatches or used to develop health and well-being apps,

338 helping users to track their $\mathrm{VO}_{2}$ max. Future research can further explore the correlation between

339 various diseases and $\mathrm{VO}_{2}$ max, as predicted using our simple and reliable method for measuring

340 CRF. 


\section{References}

343 Abut F, Akay MF, George J (2016) Developing new $\mathrm{VO}_{2}$ max prediction models from maximal,

344 submaximal and questionnaire variables using support vector machines combined with

345 feature selection. Comput Biol Med 79: 182-192.

346

https://doi.org/10.1016/j.compbiomed.2016.10.018

347 American College of Sports Medicine (2009). ACSM's Guidelines for Exercise Testing and

$348 \quad$ Prescription. Philadelphia, PA: Lippincott Williams \& Wilkins.

349 Beutner F, Ubrich R, Zachariae S, Engel C, Sandri M, Teren A, Gielen S (2015) Validation of a

350 brief step-test protocol for estimation of peak oxygen uptake. Eur J Prev Cardiol 22: 503-

351

512. https://doi.org/10.1177/2047487314533216

352

Blair SN, Kohl HW, Paffenbarger RS, Clark DG, Cooper KH, Gibbons LW (1989) Physical

353

2395-2401. https://doi.org/10.1001/jama.262.17.2395

355

356

357

358

359

360

fitness and all-cause mortality: a prospective study of healthy men and women. JAMA 262:

Buckley JP., Sim J, Eston RG, Hession R, Fox R (2004) Reliability and validity of measures taken during the Chester step test to predict aerobic power and to prescribe aerobic exercise.

Br J Sports Med 38: 197-205. https://doi.org/10.1136/bjsm.2003.005389

Cao ZB, Miyatake N, Aoyama T, Higuchi M, Tabata I (2013) Prediction of maximal oxygen uptake from a 3-minute walk based on gender, age, and body composition. J Phys Act Health 10: 280-287. https://doi.org/10.1123/jpah.10.2.280

Peer) reviewing PDF | (2020:05:48712:2:0:NEW 23 Dec 2020) 
361 Chang SC, Lin JC (1995) The validity generalization of step test as a measure of the maximal

362 oxygen intake. Physic Educ J 20: 351-362. https://doi.org/10.6222/pej.0020.199512.403

363 Grant JA, Joseph AN, Campagna PD (1999) The prediction of $\mathrm{VO}_{2}$ max: a comparison of 7

364 indirect tests of aerobic power. J Strength Cond Res 13: 346-352.

365 Culpepper MI, Francis KT (1987) An anatomical model to determine step height in step testing

366 for estimating aerobic capacity. J Theor Biol 129: 1-8. https://doi.org/10.1016/S0022-

$367 \quad 5193(87) 80199-6$

368 Jackson AS, Sui X, O'Connor DP, Church TS, Lee DC, Artero EG, Blair SN (2012) Longitudinal

369 cardiorespiratory fitness algorithms for clinical settings. Am J Prev Med 43: 512-519.

$370 \quad$ https://doi.org/10.1016/j.amepre.2012.06.032

371 Jiménez-Pavón D, Lavie CJ, Blair SN (2019) The role of cardiorespiratory fitness on the risk of

372 sudden cardiac death at the population level: a systematic review and meta-analysis of the

373 available evidence. Prog Cardiovasc Dis 62: 279-287.

$374 \quad$ https://doi.org/10.1016/j.pcad.2019.05.003

375 Kaminsky LA, Arena R, Beckie TM, Brubaker PH, Church TS, Forman DE, Franklin BA, Gulati

376 M, Lavie CJ, Myers J, Patel MJ, Piña IL, Weintraub WS, Williams MA (2013) The

377 importance of cardiorespiratory fitness in the United States: the need for a national registry: a policy statement from the American Heart Association. Circulation 127: 652-662. 
380 Kodama S, Saito K, Tanaka S, Maki M, Yachi Y, Asumi M, Sugawara A, Totsuka K, Shimano

381 H, Ohashi Y, Yamada N, Sone H (2009) Cardiorespiratory fitness as a quantitative predictor

382 of all-cause mortality and cardiovascular events in healthy men and women: a meta-

383 analysis. JAMA 301: 2024-2035. https://doi.org/10.1001/jama.2009.681

384 Laukkanen JA, Kurl S, Salonen R, Rauramaa R, Salonen JT (2004) The predictive value of

385 cardiorespiratory fitness for cardiovascular events in men with various risk profiles: a

386 prospective population-based cohort study. Eur Heart J25: 1428-1437.

387 https://doi.org/10.1016/j.ehj.2004.06.013

388 Lee O, Lee S, Kang M, Mun J, Chung J (2019) Prediction of maximal oxygen consumption

389 using the Young Men's Christian Association-step test in Korean adults. Eur J Appl Physiol

390 119: 1245-1252. https://doi.org/10.1007/s00421-019-04115-8

391 Mazic S, Zivotic-Vanovic M, Igracki I, Zivanic S, Velkovski S (2001) A simple and reliable

392 step-test for indirect evaluation of aerobic capacity. Med Pregl 54: 522-529.

393 https://doi.org/10.2478/humo-2013-000

394 McLester, C. N., Nickerson, B. S., Kliszczewicz, B. M., \& McLester, J. R. (2020). Reliability

395 and agreement of various InBody body composition analyzers as compared to dual-energy

396 X-ray absorptiometry in healthy men and women. J Clin Densitom 23:443-

397 450. https://doi.org/10.1016/j.jocd.2018.10.008 
398 Nes BM, Janszky I, Vatten LJ, Nilsen TIL, Aspenes ST, Wisløff U (2011) Estimating VO 2peak

399 from a nonexercise prediction model: the HUNT study, Norway. Med Sci Sports Exerc 43:

$400 \quad$ 2024-2030. https://doi.org/10.1249/MSS.0b013e31821d3f6f

401 O'brien RM (2007) A caution regarding rules of thumb for variance inflation factors. Qual Quant

402 41: 673-690. https://doi.org/10.1007/s11135-006-9018-6

403 Rikli RE, Jones CJ (2001) Senior fitness test manual. Human Kinetics, Champaign.

404 Ross R, Blair SN, Arena R, Church TS et al (2016) Importance of assessing cardiorespiratory

405 fitness in clinical practice: a case for fitness as a clinical vital sign: a scientific statement

406 from the American Heart Association. Circulation 134: e653-e699.

407 https://doi.org/10.1161/CIR.0000000000000461

408 Sawada SS, Lee IM, Naito H, Kakigi R, Goto S, Kanazawa M, Okamoto T, Tsukamoto K, Muto

409 T, Tanaka H, Blair SN (2014) Cardiorespiratory fitness, body mass index, and cancer

410 mortality: a cohort study of Japanese men. BMC Public Health 14: 1012.

$411 \quad$ https://doi.org/10.1186/1471-2458-14-1012

412 Stahl SE, An HS, Dinkel DM, Noble JM, Lee JM (2016) How accurate are the wrist-based heart

413 rate monitors during walking and running activities? Are they accurate enough? BMJ Open

$414 \quad$ Sport Exerc Med 2: e000106. http://dx.doi.org/10.1136/bmjsem-2015-000106 
415 Stanfield KM, Wells JC, Fewtrell MS, Frost C, Leon DA (2012) Differences in body

416 composition between infants of South Asian and European ancestry: the London Mother

417 and Baby study. Int J Epidemiol 41: 1409-1418. http://dx.doi.org/10.1093/ije/dys139

418 Su MY, Lin CC, Hsieh SY (2006) The validity and reliability of a step test with adjusted heights

419 according to leg lengths. Sports Exerc Res 8: 87-94.

$420 \quad$ https://doi.org/10.5297/ser.200606_8(2).0007

421 Sui X, LaMonte MJ, Blair SN (2007) Cardiorespiratory fitness as a predictor of nonfatal

422 cardiovascular events in asymptomatic women and men. Am J Epidemiol 165: 1413-1423.

423 http://dx.doi.org/10.1093/aje/kwm031

424 Yoopat P, Vanwonterghem K, Louhevaara V (2002) Evaluation of a step-test for assessing the

425 cardiorespiratory capacity of workers in Thailand: a pilot study. J Hu Ergol 31: 33-40.

426 https://doi.org/10.1002/car.2491 
Table $\mathbf{1}$ (on next page)

Table 1 
Table 1 Participant characteristics

\begin{tabular}{|c|c|c|c|}
\hline & Total & Training dataset & Testing dataset \\
\hline Sample size(n) & 166 & 124 & 42 \\
\hline Age(years) & $41.9+-9.6$ & $42.2+-9.4$ & $40.8+-10.2$ \\
\hline $\operatorname{Male}(\mathrm{n})$ & 65 & 44 & 21 \\
\hline Height & $164.83+-8.35$ & $164.33+-8.07$ & $166.30+-9.06$ \\
\hline Weight & $65.63+-13.60$ & $65.22+-14.08$ & $66.85+-12.15$ \\
\hline Body fat $(\%)$ & $27.81+-7.92$ & $27.79+-7.65$ & $27.86+-8.75$ \\
\hline $\mathrm{VO}_{2} \max \left(\mathrm{ml} \cdot \mathrm{kg}^{-1} \cdot \min ^{-1}\right)$ & $34.45+-8.69$ & $34.06+-8.14$ & $35.61+-10.15$ \\
\hline HR0 & $86.04+-12.78$ & $86.04+-12.99$ & $86.02+-12.29$ \\
\hline$\Delta \mathrm{HR} 3-\mathrm{HR} 0$ & $71.00+-13.24$ & $71.10+-13.41$ & $70.69+-12.87$ \\
\hline$\Delta \mathrm{HR} 3-\mathrm{HR} 4$ & $14.64+-13.72$ & $14.14+-13.94$ & $16.65+-14.09$ \\
\hline
\end{tabular}

2 Data are presented as mean \pm standard deviation

$3 H R 0$ : heart rate at the beginning 
$4 \quad \triangle H R 3-H R 0$ : difference between third minute heart rate and beginning heart rate

5 AHR3-HR4: difference between third minute and fourth minute heart rates 
Table 2 (on next page)

Table 2 
1 Table 2 Correlation between $\mathrm{VO}_{2} \max$ and features in training dataset $(\mathrm{n}=124)$

\begin{tabular}{cccccccccc}
\hline & $\mathrm{VO}_{2} \mathrm{max}$ & \multicolumn{1}{c}{$\mathrm{Sex}$} & $\mathrm{Age}$ & $\mathrm{BMI}$ & $\mathrm{BF} \%$ & $\mathrm{HR} 0$ & $\mathrm{HR} 1$ & $\mathrm{HR} 2$ & $\mathrm{HR} 3$ \\
\hline Sex & $0.597^{* *}$ & & & & & & & & \\
Age & $-0.342^{* *}$ & -0.114 & & & & & & & \\
$\mathrm{BMI}$ & -0.083 & $0.334^{* *}$ & -0.160 & & & & & & \\
$\mathrm{BF} \%$ & $-0.662^{* *}$ & $-0.491^{* *}$ & 0.109 & 0.448 & & & & & \\
$\mathrm{H} 0$ & $-0.317^{* *}$ & $-0.242^{*}$ & -0.101 & -0.058 & $0.227^{*}$ & & & & \\
$\mathrm{H} 1$ & $-0.344^{* *}$ & -0.033 & $-0.283^{*}-0.039$ & $0.274^{*}$ & $0.69^{* *}$ & & & \\
$\mathrm{H} 2$ & $-0.357^{* *}$ & $-0.312^{* *}$ & -0.093 & -0.005 & $0.308^{* *}$ & $0.592^{* *}$ & $0.899^{* *}$ & & \\
$\mathrm{HR} 3$ & $-0.289^{*}$ & $-0.254^{*}$ & $-0.21^{*}$ & 0 & $0.248^{*}$ & $0.525^{* *}$ & $0.725^{* *}$ & $0.8^{* *}$ & \\
$\mathrm{HR} 4$ & $-0.442^{* *}$ & $-0.42^{* *}$ & -0.13 & -0.063 & $0.334^{* *}$ & $0.564^{* *}$ & $0.57^{* *}$ & $0.629^{* *}$ & $0.702^{* *}$ \\
\hline
\end{tabular}

$2 \mathrm{BF} \%$ body fat percentage

$3{ }^{* *}$ Correlation coefficient is significant $(\mathrm{p}<0.001)$

$4 *$ Correlation coefficient is significant $(\mathrm{p}<0.05)$

5 
Table 3 (on next page)

Table 3 
1 Table 3 Measured versus predicted $\mathrm{VO}_{2}$ max constant error (CE) and standard deviations (SD)

2 for subgroups of the training dataset and testing dataset

\begin{tabular}{|c|c|c|c|c|c|}
\hline \multirow[t]{2}{*}{ Subgroup } & \multirow[t]{2}{*}{$\mathrm{n}(\%)$} & \multicolumn{2}{|c|}{$\mathrm{BF} \%$ model $(\%)$} & \multicolumn{2}{|c|}{ BMI model $\left(\mathrm{kg} \cdot \mathrm{m}^{-2}\right)$} \\
\hline & & $\mathrm{CE}$ & $\mathrm{SD}$ & $\mathrm{CE}$ & SD \\
\hline \multicolumn{6}{|l|}{ Training $\operatorname{set}(n=124)$} \\
\hline \multicolumn{6}{|l|}{ Sex } \\
\hline Female & $80(64.5)$ & -0.01 & 3.95 & 0.01 & 4.45 \\
\hline Male & $44(35.5)$ & -0.02 & 6.23 & 0.01 & 5.99 \\
\hline \multicolumn{6}{|l|}{ Age } \\
\hline$<40$ years & $48(38.7)$ & -0.34 & 4.72 & -0.49 & 4.94 \\
\hline $40-50$ years & $44(35.5)$ & 0.21 & 5.35 & 0.22 & 5.24 \\
\hline$>=50$ years & $32(25.8)$ & 0.17 & 4.46 & 0.47 & 4.95 \\
\hline \multicolumn{6}{|l|}{$\mathrm{VO}_{2} \max$} \\
\hline$<29 \mathrm{ml} / \mathrm{kg} / \mathrm{min}$ & $34(27.4)$ & -2.77 & 3.19 & -3.13 & 3.66 \\
\hline $29-38 \mathrm{ml} / \mathrm{kg} / \mathrm{min}$ & $56(45.2)$ & -0.22 & 4.46 & -0.22 & 4.60 \\
\hline$>=38 \mathrm{ml} / \mathrm{kg} / \mathrm{min}$ & $34(27.4)$ & 3.09 & 5.18 & 3.51 & 4.75 \\
\hline \multicolumn{6}{|l|}{ Testing $\operatorname{set}(\mathrm{n}=42)$} \\
\hline \multicolumn{6}{|l|}{ Sex } \\
\hline Female & $21(50)$ & -0.15 & 5.85 & -0.89 & 5.84 \\
\hline Male & $21(50)$ & 0.87 & 6.82 & 0.08 & 7.62 \\
\hline \multicolumn{6}{|l|}{ Age } \\
\hline$<43$ years & $24(57.1)$ & 0.67 & 6.22 & -0.07 & 6.8 \\
\hline$>=43$ years & $18(42.9)$ & -0.05 & 6.55 & -0.85 & 6.79 \\
\hline \multicolumn{6}{|l|}{$\mathrm{VO}_{2} \max$} \\
\hline$<35 \mathrm{ml} / \mathrm{kg} / \mathrm{min}$ & $22(52.4)$ & -2.88 & 4.95 & -3.86 & 5.31 \\
\hline$>=35 \mathrm{ml} / \mathrm{kg} / \mathrm{min}$ & $20(47.6)$ & 3.93 & 5.73 & 3.39 & 6.11 \\
\hline
\end{tabular}

3

4 
Table 4 (on next page)

Table 4 


\begin{tabular}{|c|c|c|c|c|c|c|}
\hline \multirow{3}{*}{$\begin{array}{l}\mathrm{VO}_{2} \max \\
\left(\mathrm{ml} \cdot \mathrm{kg}^{-1} \cdot \mathrm{min}^{-1}\right)\end{array}$} & \multicolumn{3}{|c|}{$\mathrm{BF} \%$ model $(\%)$} & \multicolumn{3}{|c|}{ BMI model $\left(\mathrm{kg} \cdot \mathrm{m}^{-2}\right)$} \\
\hline & Coefficients & $\beta$ & $p$ value & Coefficients & $\beta$ & $p$ value \\
\hline & & & & & & \\
\hline Constant & 72.334 & & .000 & 82.387 & & .000 \\
\hline Sex & 4.366 & 0.258 & .000 & 9.338 & 0.551 & .000 \\
\hline$(0=$ women, $1=$ me & & & & & & \\
\hline $\operatorname{Age}(\mathrm{yr})$ & -0.261 & -0.302 & .000 & -0.327 & -0.378 & .000 \\
\hline Body composition & -0.448 & -0.421 & .000 & -0.718 & -0.346 & .000 \\
\hline HR0 & -0.134 & -0.214 & .001 & -0.171 & -0.273 & .001 \\
\hline$\triangle \mathrm{HR} 3-\mathrm{HR} 0$ & -0.082 & -0.136 & .041 & -0.099 & -0.163 & .017 \\
\hline$\Delta \mathrm{HR} 3-\mathrm{HR} 4$ & 0.073 & 0.124 & .048 & 0.081 & 0.139 & .032 \\
\hline $\mathrm{R}^{2}$ & 0.624 & & & 0.567 & & \\
\hline SEE & 4.982 & & & 5.153 & & \\
\hline
\end{tabular}


$\mathrm{SEE} \% \quad 14.46$

14.96

PRESS

2904.186

3107.325

SEEp

4.840

5.006

$\mathrm{R}^{2} \mathrm{p}$

0.644

0.619

2 BMI: body mass index

$3 B F \%$ : body fat percentage

$4 \beta$ : standardized regression weights

5 SEE: standard error of estimate

$6 S E E \%: \mathrm{SEE} /$ mean of measured $\mathrm{VO}_{2} \max \times 100$.

7 PRESS: predicted residual error sum of squares

8 SEEP: PRESS standard error of estimate

$9 \quad R^{2} p$ : PRESS squared multiple correlation coefficient

10 
Figure 1

Fig 1

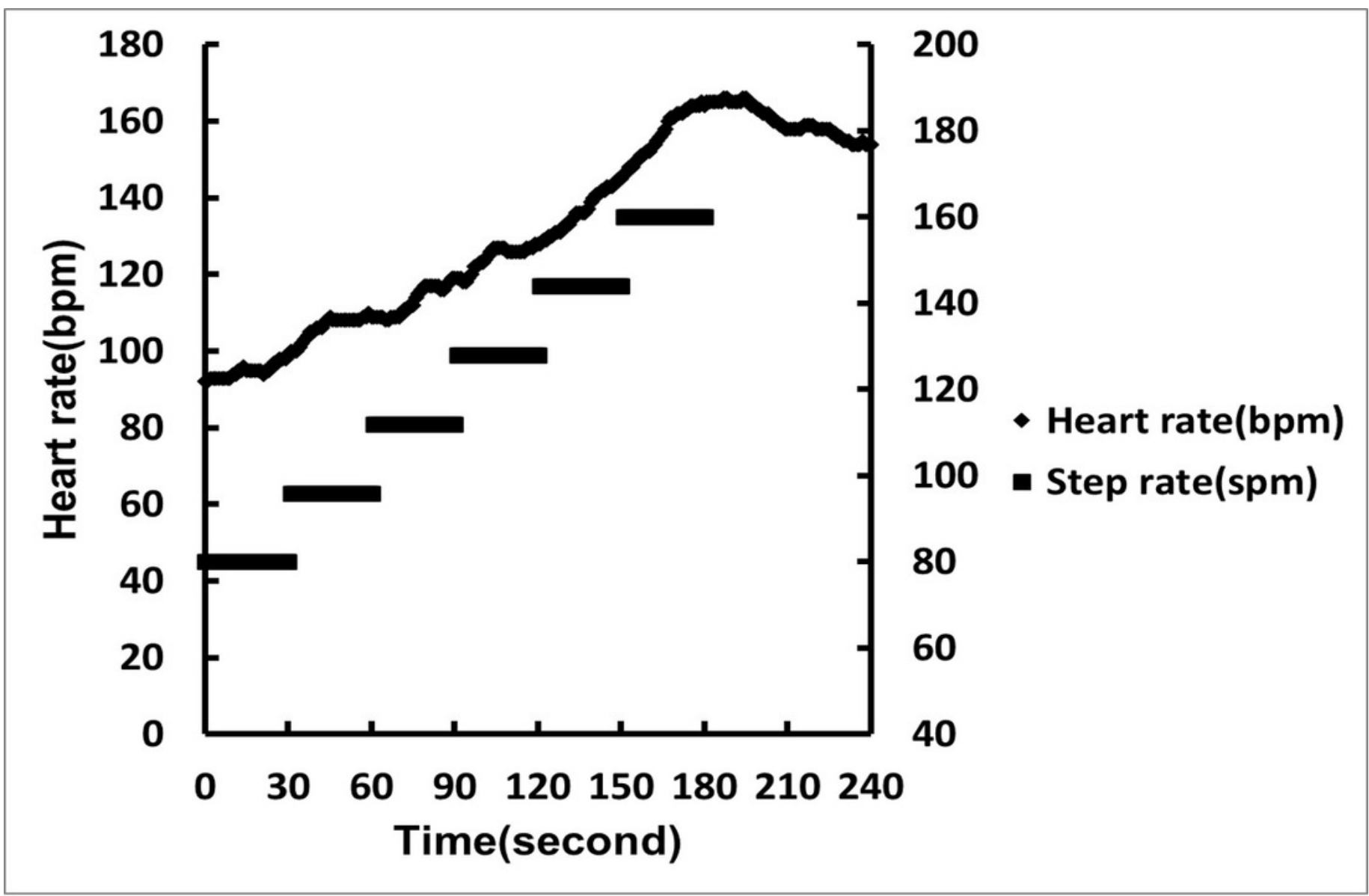

Fig. $13 \mathrm{MPKS}$ heart rate model and corresponding step frequency 
Figure 2

Fig 2

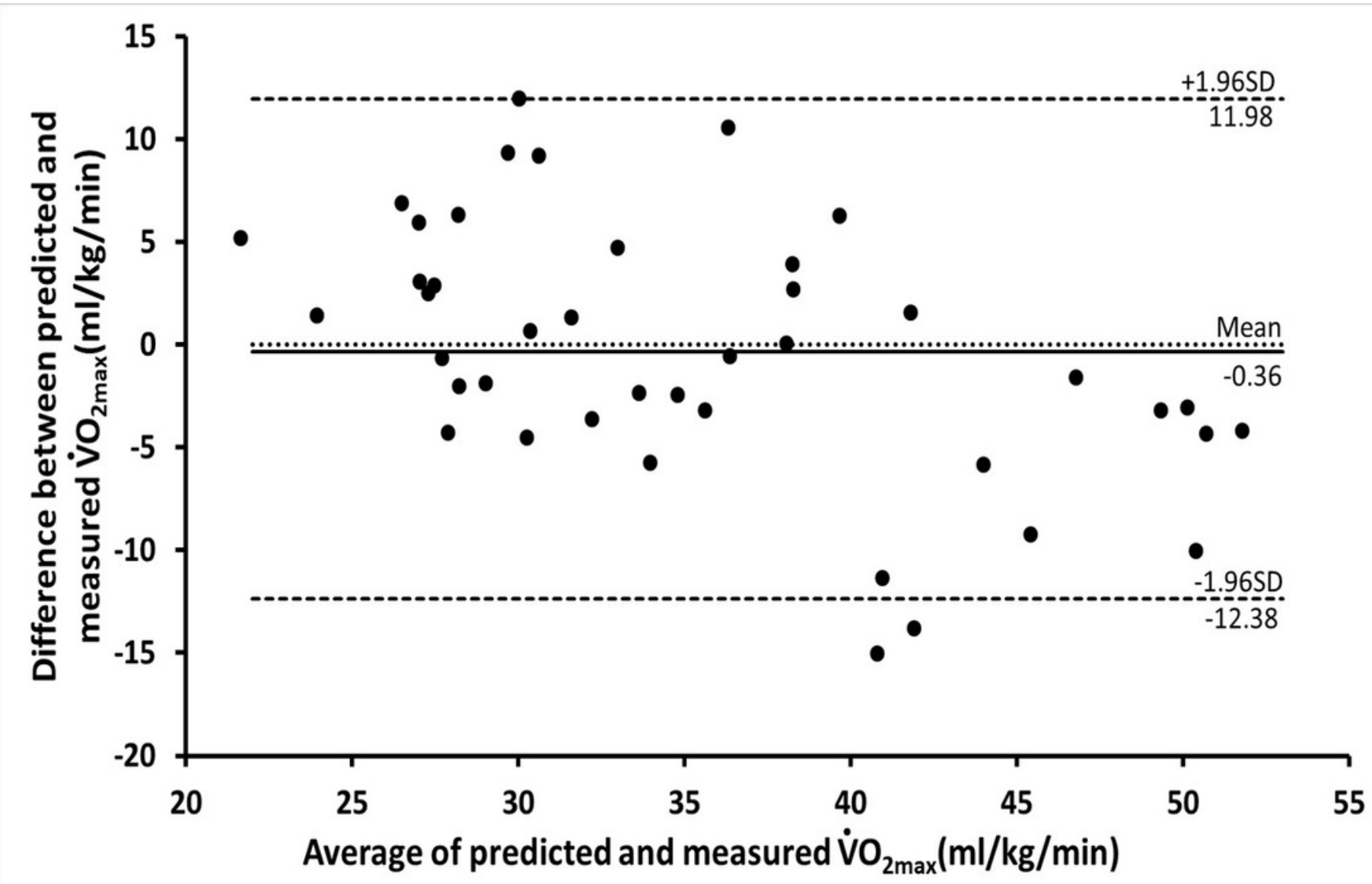

Fig. 2 Bland Altman plot, including limits of agreement, for predicted and measured $\mathrm{VO}_{2}$ $\max (\mathrm{ml} / \mathrm{kg} / \mathrm{min})$ of $\mathrm{BF} \%$ model by testing dataset $(\mathrm{n}=42)$. Black line mean difference.

Dashed line $\pm 1.96 \times$ SD 
Figure 3

Fig 3

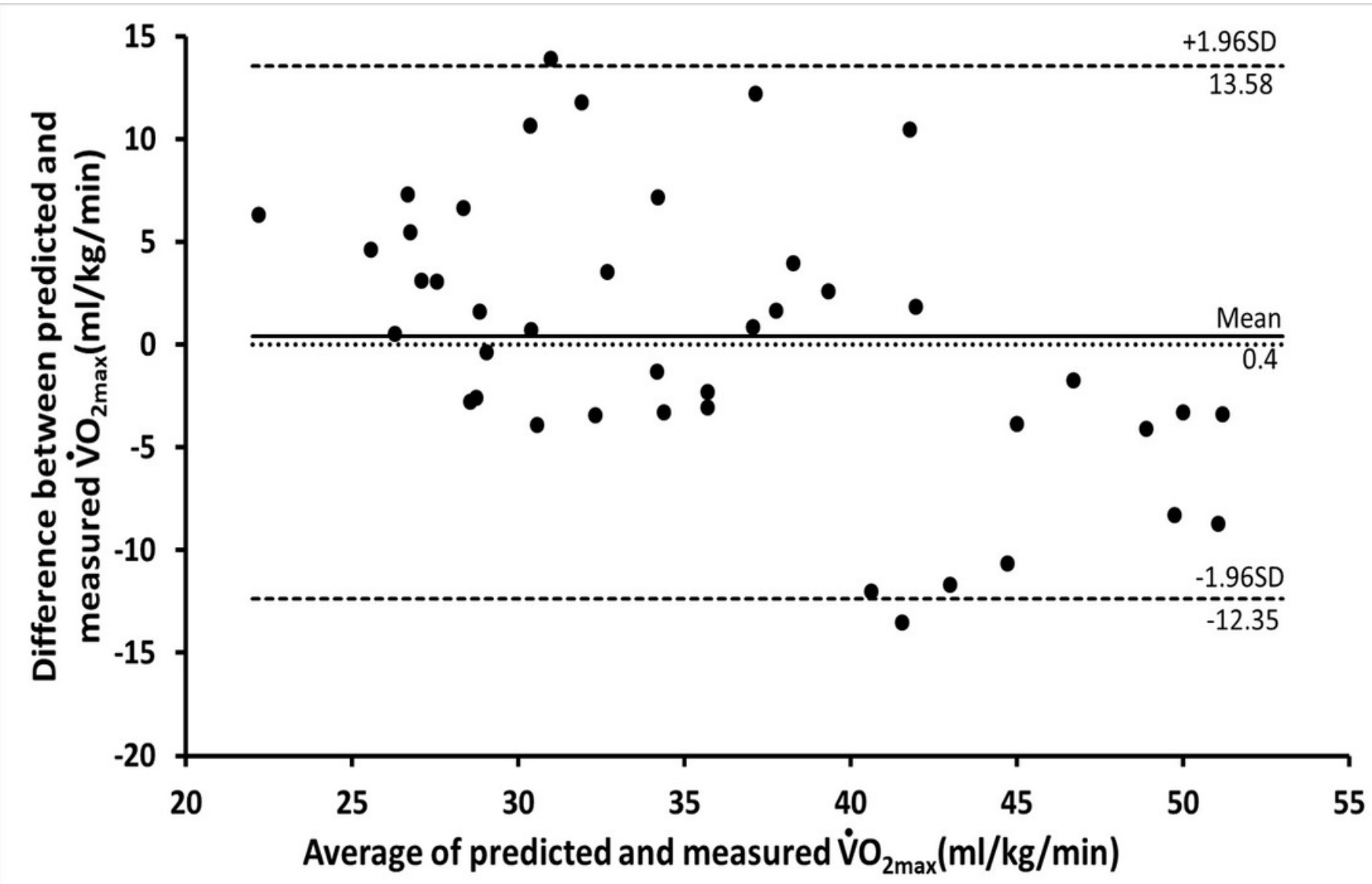

Fig. 3 Bland Altman plot, including limits of agreement, for predicted and measured $\mathrm{VO}_{2}$ $\max (\mathrm{ml} / \mathrm{kg} / \mathrm{min})$ of BMI model by testing dataset $(\mathrm{n}=42)$. Black line mean difference.

Dashed line $\pm 1.96 \times \mathrm{SD}$ 
Figure 4

Fig 4

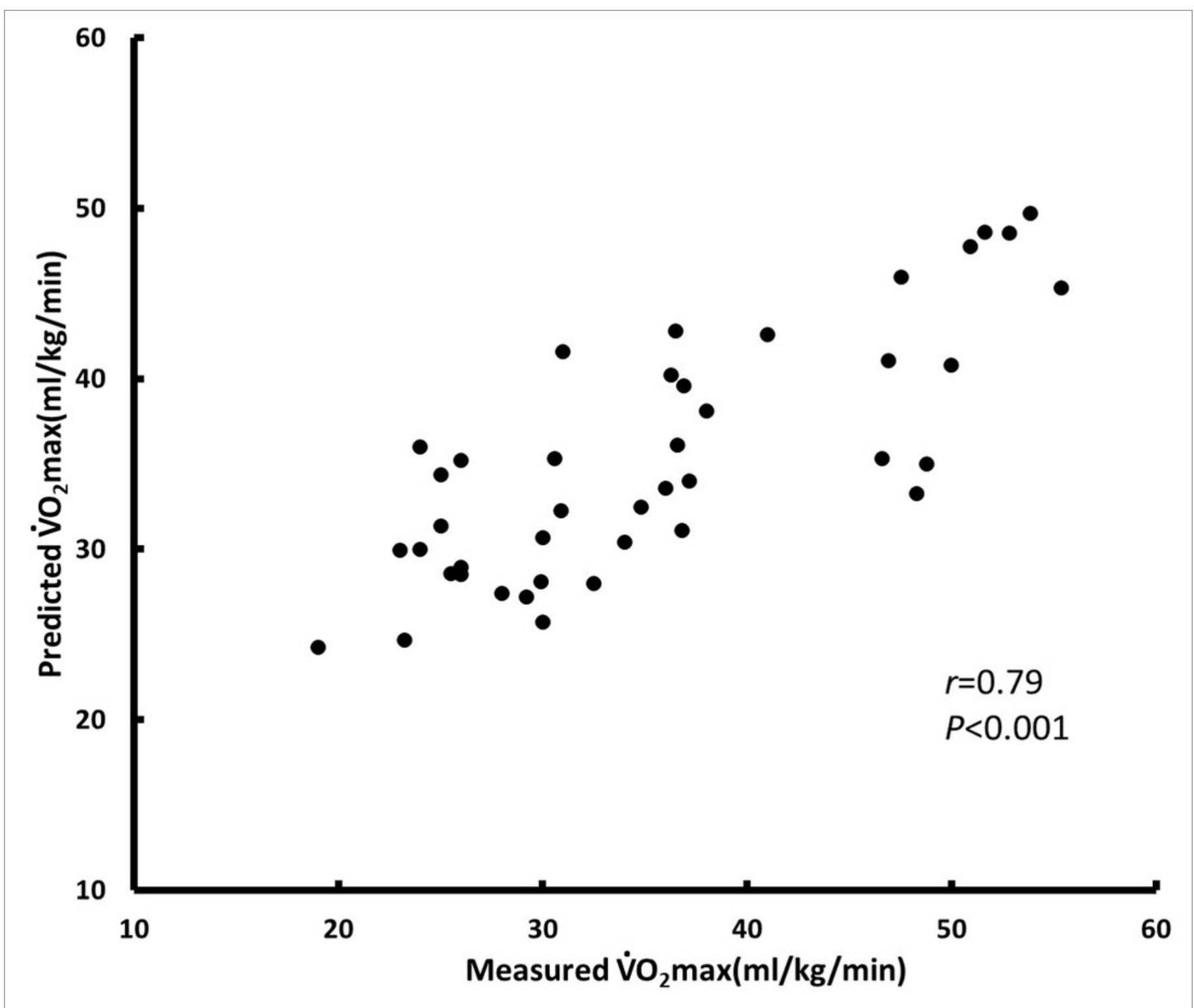

Fig. $4 \mathrm{BF} \%$ model for testing set $(\mathrm{n}=42)$ 
Figure 5

Fig 5

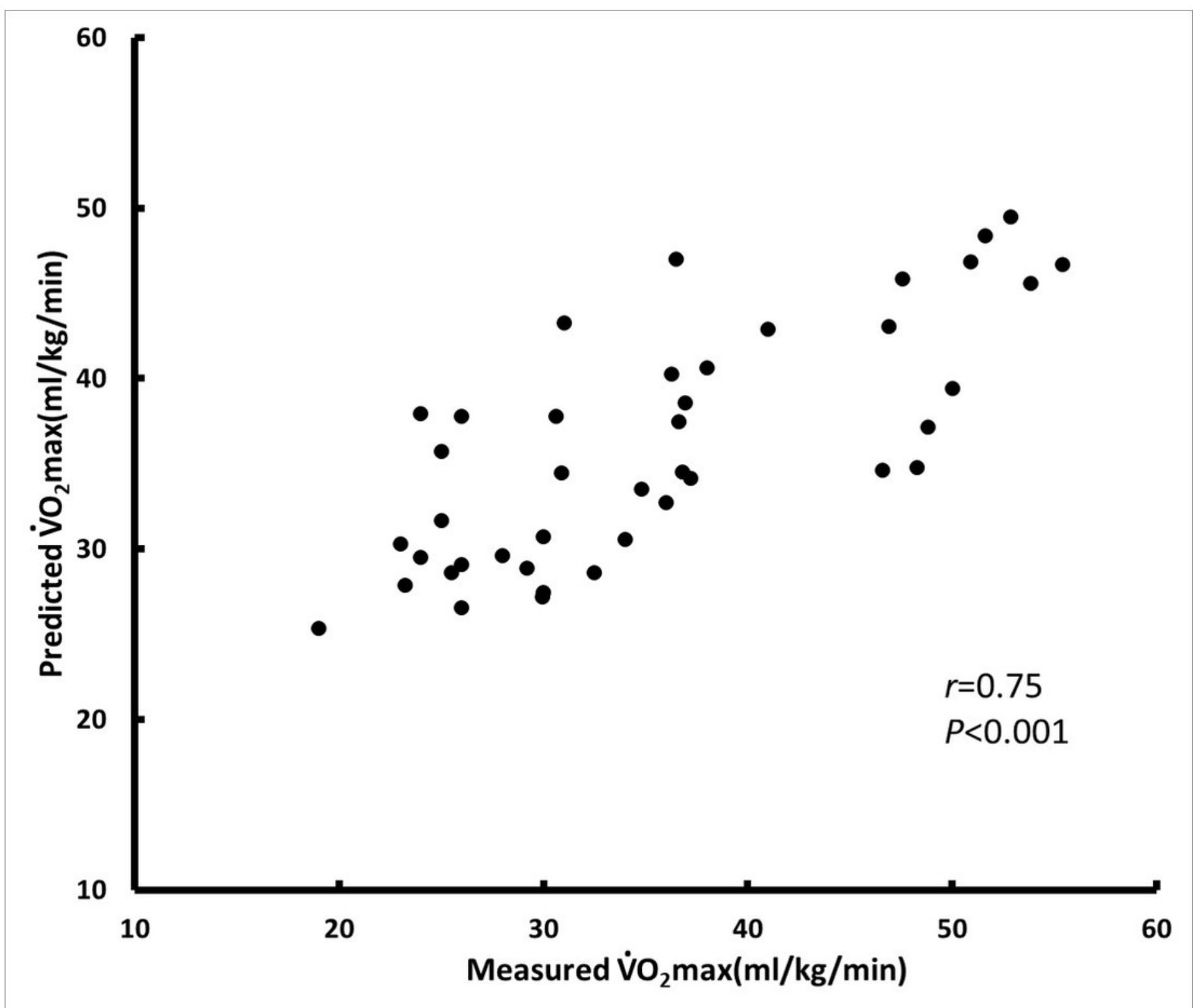

Fig. 5 BMI model for testing set $(n=42)$ 